\title{
Interactive comment on "DISCOL experiment revisited: Assessing the temporal scale of deep-sea mining impacts on sediment biogeochemistry" by Laura Haffert et al.
}

\section{Anonymous Referee \#2}

Received and published: 31 December 2019

Haffert and co-authors present a comprehensive sedimentary geochemical dataset on an experimentally disturbed potential deep-sea mining area, called DISCOL. The paper reports an extensive set of downcore geochemical data (O2, organic $\mathrm{C}$, nutrients) from both short (MUC, box corer) as well as long (GC) cores in the experimental site. Further, the study improves an existing diagenetic reaction-transport model with datadriven process optimisations. The authors then use these new data plus transient early diagenetic simulations to asses the short and long-term impact of sediment removal during (future) mining of polymetallic nodules. They find that the removal of the surface labile organic carbon along with the nodules is the single most important driver of the establishment of a new geochemical regime in the disturbed areas. 
The primary strength of this work is a quite convincing set of predictions as to what will happen in the long run when these nodules will be extracted from the seabed. The transient simulations are very useful and well integrated to the data. Supported by an extensive and novel dataset and the improved modelling approach, the integrated methodology could be used in other seafloor resource extraction scenarios as well.

There is no significant weakness in the manuscript. It is well laid out and well written. I only have a few suggestions for a minor revision of the existing manuscript:

Overall comment: How does the Fe(II)-rich clay layer can trap nitrate? The redox reaction between the two is not that well established, and wondering if a more complex cycle is present here, involving nitrogen intermediate species and a more complicated $\mathrm{Fe}(\mathrm{II})-\mathrm{Fe}$ (III) cycle. I would propose that Figure 2 can be improved to clarify this, and both introduction (L84) and discussion parts can be expanded with a more detailed proposition of redox pathways.

L27: JPI Oceans - with plural 'oceans', I think is the right acronym.

L54: the work 'untypically' can be removed without a significant change in the meaning of the sentence.

L58: 'availability positions' - perhaps could be re-phrased using 'order of the electron acceptors' or similar.

Section 1.1 - overall I find this section is more like a discussion, rather than introduction. As mentioned above, the introduction of a Fe(II)-NO3 redox pathway is a little bit out of place in this section. Besides, the readers might expect a following section of 1.2, since there is 1.1 , bot there is no other subsection of the introduction. Please consider re-organizing the material in 1.1.

Printer-friendly version

L200-205 - interesting - did all cores include such buried nodule layers? I would strongly recommend to indicate the depth of these layers in the Figures 3-6 to be able to see directly in the figure if the nodule is impacting the geochemical profiles. 
Interactive comment on Biogeosciences Discuss., https://doi.org/10.5194/bg-2019-361, 2019.

Interactive

comment 